\title{
SOURCE PARAMETERS OF MODERATE AND STRONG EARTHQUAKES IN THE BROADER AREA OF ZAKYNTHOS ISLAND (W. GREECE) FROM REGIONAL AND TELESEISMIC DIGITAL RECORDINGS
}

\author{
Chousianitis K. ${ }^{1}$, Agalos A. ${ }^{1}$, Papadimitriou P. ${ }^{1}$, Lagios E. ${ }^{1}$ \\ and Makropoulos K.1 \\ ${ }^{1}$ Department of Geophysics-Geothermics, National \& Kapodistrian University of Athens, \\ 15784 Panepistimiopolis - Greece, chousia@geol.uoa.gr,aagalos@geolo.uoa.gr,ppapadim@geol.uoa.gr, \\ lagios@geol.uoa.gr,kmacrop@geol.uoa.gr
}

\begin{abstract}
The source parameters of all the moderate and strong events that occurred in the broader area of Zakynthos Island for the period 1997-2009 are determined using two different techniques depending on epicentral distance. For the strong events we employed teleseismic body-wave modeling between $30^{\circ}$ and $90^{\circ}$, while for moderate events a regional moment tensor inversion approach was used. In both cases we used broadband waveform data with a good signal-to-noise ratio. The calculated focal mechanisms are representative of the displacement and strain fields of the broader area. Those associated with the Cephalonia transform fault are consistent with dextral strike-slip motion. The area between the island of Zakynthos and the Western coast of Peloponnese is also characterized by strike-slip faulting, while reverse faulting is mainly observed south of Zakynthos Island. Using both techniques, we also retrieved the source parameters of the biggest events of the seismic sequence of April 2006 near the southern coast of Zakynthos Island. The depths of the located events of the sequence vary mainly between 10 and $25 \mathrm{~km}$. The fault plane solutions revealed thrust type faulting in all cases, something which can be related with upward motions in the southern part of the Island observed by DGPS measurements.
\end{abstract}

Key words: source parameters, teleseismic modeling, moment tensor inversion, Zakynthos Island.

\section{Introduction}

Body-wave modeling has proven quite effective in determining the earthquake source parameters (eg. Kikuchi \& Kanamori, 1991; Kikuchi et al., 1993; Papadimitriou P., 1983; Papadimitriou et al., 2006; Chousianitis, 2009). It can be divided into teleseismic and regional depending on the epicentral distance of the recorded phases. The magnitude threshold for source parameters determination using teleseismic body-wave modeling is approximately $\mathrm{M}_{\mathrm{w}}=5.7$, as teleseismic phases become too weak for smaller events and thus regional data must be used, which are generally much more complicated by strong interaction with the heterogeneous crust and upper mantle structures (Papadimitriou P., 1988). However at regional distances the above mentioned threshold is lowered to approximately $\mathrm{M}_{\mathrm{w}}=3.8$, and frequency-magnitude relations have lead to the obvious conclusion that regional-distance modeling has allowed researchers to increase the number of studied events, especially in areas with regional broadband instrumentation (Saikia et al., 2001; Agalos et al., 2008). 
Two kinds of regional waveform data are typically used for source estimation, surface waves (Thio \& Kanamori 1995) and body waves (Fan et al., 1994; Dreger \& Helmberger, 1993). In the present study body waves are used, which are generally less affected by shallow heterogeneities and are more stable than surface waves, although they have a lower signal-to-noise ratio due to their smaller energy. In general, the teleseismic body waves contain the information on the overall moment release rate and the depth range of the rupture area, while regional waveforms contain most of the information on the detailed slip process in the source area. Therefore, it is important to use both the teleseismic body wave and regional data to estimate the detailed and stable source process.

The most reliable solutions of 100 events, taking into account the station coverage and the correlation error related to the fitting of the synthetics to the data, that occurred during the time interval from 1997 until 2009 in the broader area of Zakynthos Island are presented in this study. The objective of this paper is to present a dense database of regional focal mechanisms for intermediate and strong events which fully cover the broader area of Zakynthos Island, a very active region of particular scientific interest. Synthetic seismograms were generated for P, SH and SV broadband waveform data in order to determine the strike, dip and rake of the fault plane, the centroid depth, the seismic moment and the source time function of each modeled earthquake. For the implementation of teleseismic modeling the data used comes from the IRIS (Incorporated Research Institutions for Seismology) Global Digital Seismographic Network (GDSN), while the observed waveforms for regional modeling were taken from stations belonging mainly to the Hellenic Unified Seismological network, as well as stations from Mednet and Geofon networks. At the same time, we were able to study the strongest events of the seismic sequence that occurred near the southern coast of Zakynthos Island during April and May 2006 and correlate them with DGPS results. These measurements carried out on Zakynthos Island for the time period August 2005 - July 2006 revealed intense uplift in the southern part of the Island, bounding the area of Laganas Bay (Lagios et al., 2007; Chousianitis, 2009).

\section{Geological-Tectonic Setting}

The study area is located in Western Greece, near the boundary between the African and the Eurasian lithospheric plates, at the northwestern end of the Hellenic Arc - Trench System. This boundary comprises a zone of volcanic activity and intense seismicity that results in numerous earthquakes and extends along South Ionian Sea and Western Peloponnesus, continues along the islands of Kythera and Antikythera to south of Crete and terminates to Rhodes Island. The plate movements along the Hellenic Arc - Trench System and the associated seismicity have also formed a series of sea basins extending from Cephalonia to Rhodes. This zone has been formed along the boundary of the two lithospheric plates as the northern segment of the African plate south of the Adriatic Sea, which comprises the Eastern Mediterranean oceanic lithosphere, is subducted beneath the higher density continental lithosphere of Eurasia - part of which is the Aegean microplate (Le Pichon \& Angelier, 1979). This subduction zone terminates against the Cephalonia transform fault, a major dextral strike-slip fault, which follows the submarine Cephalonia valley west of the island chain from Lefkas to Cephalonia and links this subduction with the continental collision between the Apulia microplate and the Hellenic Foreland, which is observed north of Lefkada (Finetti \& Morreli, 1973; Scordilis et al., 1985; Anderson \& Jackson, 1987; Papadimitriou P., 1988) (Fig. 1).

The broader area of Zakynthos Island is presently one of the most seismo-tectonically active areas not only in Greece, but also in the entire Mediterranean region (Jackson \& McKenzie, 1988). This is reflected on the existed comprehensive catalogues of seismic events for Greece, where the occurrence of more than 4500 intermediate-size earthquakes during the last 50 years, with several large and de- 


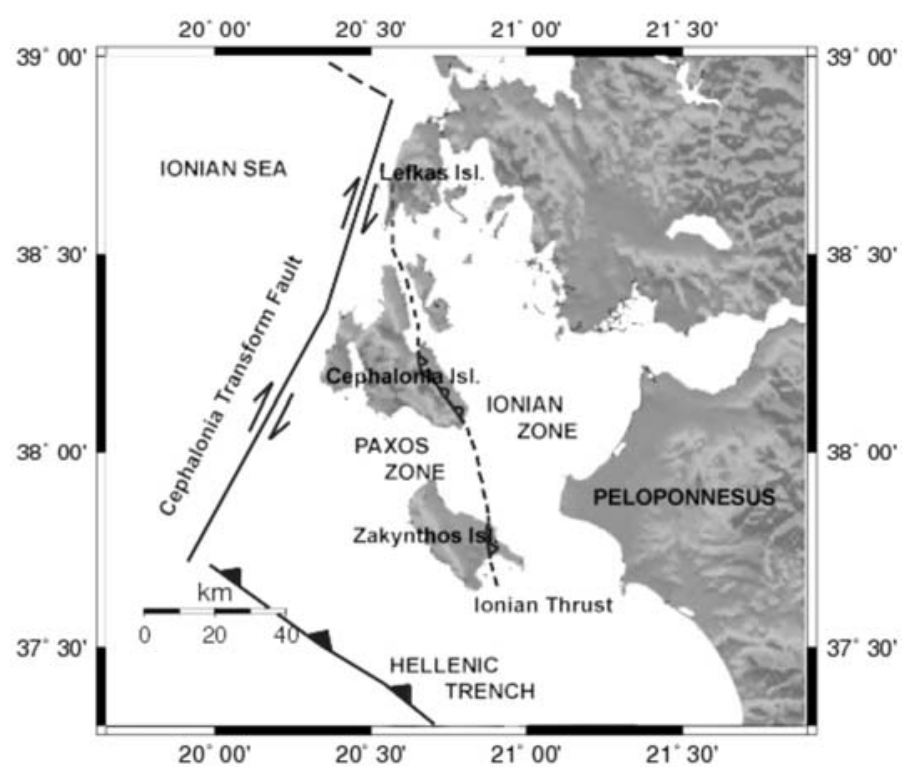

Fig. 1: Main tectonic features of Central Ionian Islands. The subduction zone (line with teeth), the Cephalonia transform fault (arrows) and the continental collision boundary (dashed line) are shown.

structive events among them, can be confirmed (Makropoulos \& Burton, 1981). The area is characterized by horizontal compression almost perpendicular to the Hellenic Arc, which is thought to have been initiated during the Miocene (Hatzfeld et al., 1990). Consequently, most of the earthquakes in this particular region of the Hellenic Arc involve reverse motion. Palaeomagnetic studies of Cenozoic rocks in the Aegean region (Kissel \& Laj, 1988) demonstrate that parts of Western Greece have undergone substantial clockwise rotation during the Neogene simultaneously with compression.

The geology of the study area is characterized by complex structural and stratigraphic features. Two geotectonic zones from west to east are defined, the Pre-Apulian or Paxos and the Ionian, with their boundary being the Ionian thrust, which is considered to represent the most external Hellenide structure. These geotectonic zones are defined on the basis of different sedimentary facies of exposed Mesozoic and Cenozoic rocks and different tectonic styles. Compressive tectonism related to Alpine deformation and major recurrent movement of evaporite successions during both Mesozoic and Cenozoic time has produced complicated folding and different type of faulting. The Pre-Apulian Zone experienced significant late Neogene and Quaternary shortening (Underhill, 1989). The corresponding stratigraphy of Paxos zone contains a thick series of Mesozoic to Palaeogene carbonates that are overlain by a series of folded Oligocene to earliest Tortonian deepmarine marls and interbedded turbiditic calcareous sandstones (Underhill, 1989). Respectively, the known stratigraphic succession consists of 6000-7000 m of chiefly carbonate and evaporite strata of Triassic to Eocene age overlain by 1000-4000 m of Oligocene and Lower Miocene flysch deposits.

\section{Teleseismic Body-Wave Modeling}

A teleseismic body-wave modeling was employed in order to determine the source parameters of the largest events that occurred in the broader area of Zakynthos Island for the past decade. At these dis- 
tances, the shape of the seismic waves depend upon both the depth of the source and the orientation of the nodal planes and they have paths that lie almost entirely within the lower mantle and are not affected by the local structure of the upper mantle. In the present analysis, the source parameters have been constrained by a visual comparison between observed and synthetic waveforms on a trial and error basis. The waveform data used consisted of digital recordings obtained from the Incorporated Research Institution for Seismology (IRIS) and Global Digital Seismographic Network (GDSN) broadband components.

The calculation of a synthetic seismogram $W(t)$ is based on the convolution of four linear operators:

where $U(t)$ is the far-field displacement, $S(t)$ is the source time

function, $Q(t)$ is the attenuation and $I(t)$ is the instrument response. The far-field wave displacement recorded at azimuth $\phi$ and epicentral distance $\Delta$, is calculated using the formula (Kanamori \& Stewart, 1976; Aki \& Richards, 1980):

where $U(t)$ is the vertical, radial or transverse displacement in case of P-, SH- or SV-waves, respectively, $g(\Delta)$ is the geometric spreading, $\alpha$ is the Earth radius, $R$ denotes the radiation pattern in case of P-, SH- or SV-waves, $c$ denotes the Vp or Vs velocity, $\varrho$ is the density, $i_{h}$ and $i_{0}$ is the angle of incidence at the source and the receiver respectively, $C$ is the free surface effect and $M_{0}$ is the seismic moment.

Only seismograms recorded at epicentral distances between $30^{\circ}$ and $90^{\circ}$ with a good signal-to-noise ratio were used, a constraint that ensures the avoidance of complexities due to the upper mantle response and to core phase effects. Body waves at these distances do not experience triplication or diffraction near the core-mantle boundary that severely complicate the observed waveforms. Instrument responses were deconvolved from the original recordings to obtain true ground displacement records. The waveforms were band-pass filtered generally at corner frequencies $\mathrm{f} 1=0.02 \mathrm{~Hz}$ and $\mathrm{f} 2=0.2 \mathrm{~Hz}$ using a Butterworth filter in order to remove the high frequency noise and to attain a good signal-to-noise ratio. In addition, for the estimation of the attenuation factor $\mathrm{Q}(\mathrm{t})$, we used Futterman's operator with $\mathrm{t}^{*}$ equal to 1 second for P waves and 4 seconds for SH and SV waves (Futterman, 1962). Overall we computed the source parameters of six earthquakes close to Zakynthos Island with moment magnitudes $\mathrm{M}_{\mathrm{w}}>5$.4. Information on the focal parameters of the events studied is given in Table 1.

Table 1. Source parameters determined by teleseismic waveform modeling.

\begin{tabular}{|c|c|c|c|c|c|c|c|c|}
\hline Date & $\begin{array}{c}\text { Origin } \\
\text { Time }\end{array}$ & $\mathbf{M}_{w}$ & $\begin{array}{c}\mathbf{M}_{\mathbf{0}} \\
(\mathbf{d y n} \cdot \mathbf{c m})\end{array}$ & $\begin{array}{c}\text { Depth } \\
(\mathbf{k m})\end{array}$ & $\begin{array}{c}\text { Source } \\
\text { Duration } \\
(\mathbf{s e c})\end{array}$ & $\begin{array}{c}\text { Strike } \\
\mathbf{(}^{\mathbf{9}} \mathbf{)}\end{array}$ & $\begin{array}{c}\text { Dip } \\
\left.\mathbf{(}^{\mathbf{}}\right)\end{array}$ & $\begin{array}{c}\text { Rake } \\
\left({ }^{\mathbf{0}}\right)\end{array}$ \\
\hline $18 / 11 / 1997$ & $13: 07$ & 6.5 & $0.8 \cdot 10^{26}$ & 40 & 10 & 116 & 86 & 70 \\
\hline $31 / 01 / 2005$ & $01: 05$ & 5.6 & $3.5 \cdot 10^{24}$ & 10 & 4 & 342 & 12 & 115 \\
\hline $18 / 10 / 2005$ & $15: 25$ & 5.7 & $5.5 \cdot 10^{24}$ & 15 & 4,5 & 12 & 15 & 130 \\
\hline $11 / 04 / 2006$ & $00: 02$ & 5.4 & $1.8 \cdot 10^{24}$ & 18 & 4 & 142 & 59 & 70 \\
\hline $11 / 04 / 2006$ & $17: 29$ & 5.5 & $2.5 \cdot 10^{24}$ & 13 & 4 & 140 & 70 & 85 \\
\hline $12 / 04 / 2006$ & $16: 52$ & 5.6 & $3.5 \cdot 10^{24}$ & 13 & 4 & 25 & 25 & 135 \\
\hline
\end{tabular}




\section{Regional Moment Tensor Inversion}

The seismic moment inversion method is widely employed in determining focal mechanisms from local and regional broadband seismograms via the production of reliable synthetic waves at distances less than $1000 \mathrm{~km}$. The advantage of this approach is that the magnitude threshold of events that can be analyzed has been lowered to less than 4 comparing to teleseismic waveform modeling. The method of $\mathrm{P}$ arrivals, for a long time, was the only method that could be used with regional and local waveforms in order to reveal the focal mechanism. Recently it was succeeded, to produce reliable regional synthetic waves (Fukuyama \& Dreger, 2000; Ichinose et al., 2003). From that moment it was quite easy to use the regional waveforms and the produced synthetic ones to calculate source parameters through a linear inversion procedure. One of the inversion methods is the frequency-wavenumber (F-K) integration method (Saikia, 1994; Zeng \& Anderson, 1995; Bouchon, 2003). This method which is applied in the present study mainly for moderate earthquakes, calculates synthetic waves directly compared with the observed ones for a given velocity structure. Synthetics were generated using the reflectivity and frequency-wavenumber summation technique proposed by Zeng and Anderson, (1995). This code based on the generalized reflection and transmission coefficient method computes 10 fundamental Green functions as it is described by Herrmann and Wang, (1985). These 10 Green functions are then combined together with the moment tensor elements in order to produce the 3 components of motion for a known focal mechanism known as the tangential, radial and vertical component as proposed by Jost and Herrmann, (1989). In more detail the methodology computes differential seismograms directly in a layered elastic half-space. First the medium velocity differential field is computed with respect to the velocity change in the layer and then multiplies it by the original elastic wave field. The obtained differential waves are propagated directly to the receiver using the generalized R/T matrix method. The synthetics are calculated using the discrete wavenumber summation and imaginary frequency technique (Bouchon, 1979). The applied moment tensor inversion used the codes of Ichinose et al. (2003), for different source depths.

A very significant parameter which is strongly connected with the quality of the obtained focal mechanism solution is the azimuthal coverage. In order to minimize the bad effects of the possible poor azimuthal coverage we used only stations with good signal to noise ratio. The observed waveforms for the selected earthquakes were taken from stations belonging to the Unified Hellenic network and to the Mednet and Geofon networks with a good signal to noise ratio. In most cases we used at least three or four stations. The strong ones were modeled using data from more than eight stations. In all cases for the presented solutions the fit between observed data and synthetics was quite good. Instrument responses were deconvolved to receive pure displacement. The regional broad-band data were also band-pass filtered in frequencies between 0.01-0.05 Hz for events larger than $\mathrm{M}_{\mathrm{w}}>5.0$ and between $0.02-0.05 \mathrm{~Hz}$ for events with $\mathrm{M}_{\mathrm{w}}<5.0$. Finally the horizontal components were rotated to the radial and tangential components. Over 100 earthquakes which occurred in the broader area of Zakynthos Island have been modeled using this method for the time period 1997-2008 (Fig. 2a).

\section{Strongest Events of April 2006 Seismic Sequence}

Using both regional and teleseismic modeling, we also obtained a significant number of focal mechanism solutions belonging to the seismic sequence of April 2006 near the southern coast of Zakynthos Island (Fig. 2b). In the following section we discuss the modeling results at regional and teleseismic distances for two of the strongest events of the sequence, which occurred on 4 and 12 April respectively. 

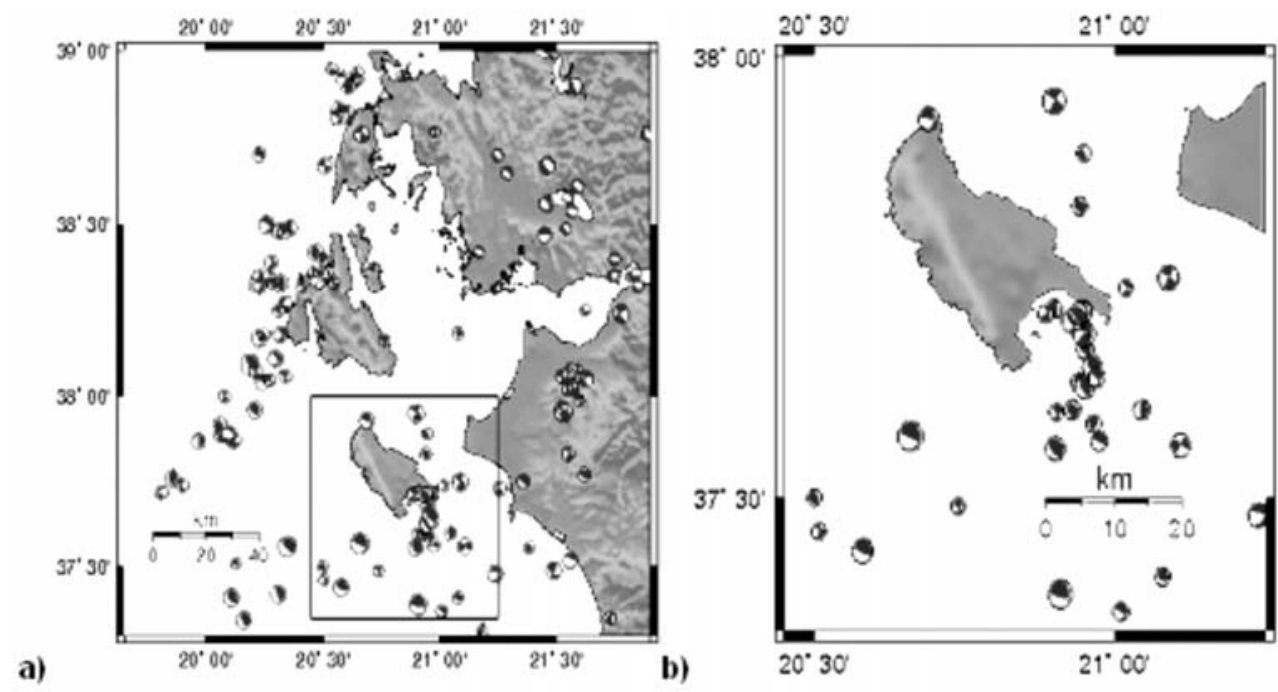

Fig. 2: a) Focal mechanism solutions of moderate and strong earthquakes for the period between 1997 and 2008. Black quadrants denote compression and white dilatation. b) Focal mechanism solutions belonging to the seismic sequence of April 2006.
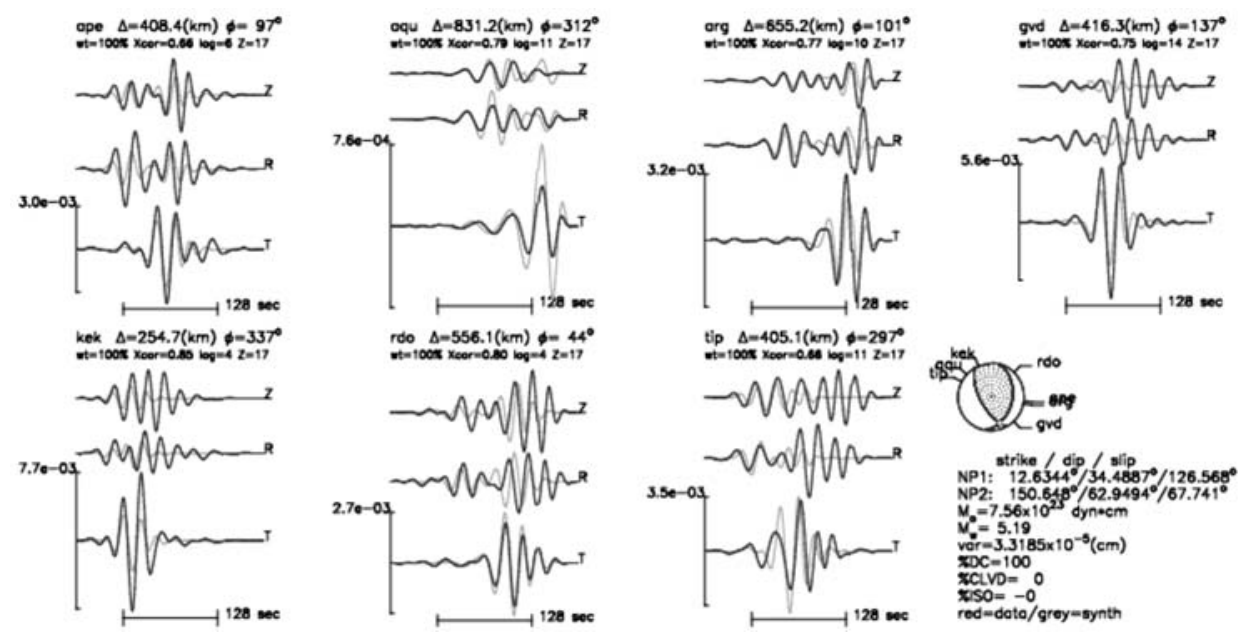

Fig. 3: Best fit focal mechanism obtained from comparison between synthetic and observed regional broad-band records for the April 4, 2006 (22:05), $\mathrm{M}_{\mathrm{w}}=5.2$ earthquake.

\section{Event of April 4, 2006 (22:05)}

On April 4, 2006 (22:05 GMT) the first earthquake of magnitude $\mathrm{M}_{\mathrm{w}}=5.2$ of a series of four events, belonging to the seismic sequence of April 2006, with magnitudes $M_{w}>5.0$ occurred. The epicenter of this event $\left(20.951^{\circ} \mathrm{E}, 37.626^{\circ} \mathrm{N}\right)$ was located near the southern coast of Zakynthos Island and was felt in the broader area. The lack of available data at teleseismic distances led us to employ the seismic moment tensor inversion method for regional broadband seismograms at distances less than 


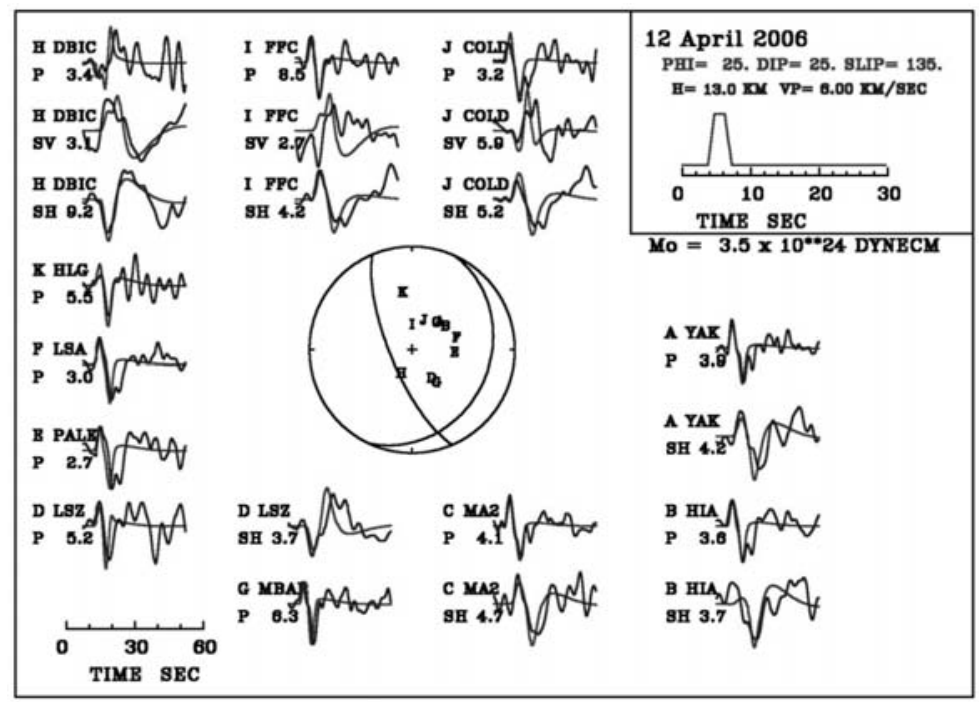

Fig. 4: Best fit focal mechanism and source time function (inset) obtained from comparison between synthetic and observed broad-band records for the April 12, 2006 (16:52) earthquake.

$1000 \mathrm{~km}$. The production of reliable synthetic waveforms revealed thrust faulting with strike $=13^{\circ}$, $\operatorname{dip}=34^{\circ}$ and rake $=127^{\circ}$, while the focal depth is $17 \mathrm{~km}$ and the seismic moment of the order of $7.56 \cdot 10^{23}$ dyn $\cdot \mathrm{cm}$ (Fig. 3). The focal mechanism reported by Harvard (strike $=359^{\circ}, \mathrm{dip}=25^{\circ}$, rake $=117^{\circ}$, depth $=19.5 \mathrm{~km}$ ) is not far from the solution shown in figure 3 .

\section{Event of April 12, 2006 (16:52)}

On April 12, 2006 (16:52 GMT) the strongest event $\left(\mathrm{M}_{\mathrm{w}}=5.6\right)$ of the seismic sequence of 2006 occurred. The epicenter $\left(20.963^{\circ} \mathrm{E}, 37.648^{\circ} \mathrm{N}\right)$ is located at the same area with the one of the April $4^{\text {th }}$ earthquake and a few kilometres south of the epicenters of the events that took place the previous day. The available data allowed us to employ teleseismic body-wave modeling. Synthetic waveforms were generated using a simple trapezoidal source time function of $4 \mathrm{sec}$ duration. Here, 11 teleseismic stations with good azimuthal coverage for the generation of $\mathrm{P}$ waves, 7 for SH waves and 3 for SV waves were used. The selected stations provide a satisfactory azimuthal coverage of the focal sphere, which helped us to accurately define the nodal planes of the focal mechanism. Finally, the obtained focal parameters revealed fault plane solution with strike $=25^{\circ}$, dip $=25^{\circ}$, rake $=135^{\circ}$, which indicates thrust faulting. The seismic moment is equal to $3.5 \cdot 10^{24} \mathrm{dyn} \cdot \mathrm{cm}$, and the focal depth was found to be $13 \mathrm{~km}$. The result obtained by the method shows quite satisfactory fitting between the observed and the synthetic waveforms for both P, SH and SV waves (Fig. 4). The focal mechanism reported by Harvard for this event $\left(\operatorname{strike}=2^{\circ}, \operatorname{dip}=23^{\circ}\right.$, rake $=121^{\circ}$ ) is in a good agreement with the calculated one, while the estimated depth $(20.5 \mathrm{~km})$ is slightly different. However, fixing the depth equal to that of the Harvard solution, the synthetics displayed a mismatch shape with the observed.

All the calculated fault plane solutions of the April 2006 seismic sequence are distributed on a NWSE direction, and revealed a compressional regime, with a small differentiation in the direction (Fig. 2). The focal depths of the most hypocenters are confined between 10 and $25 \mathrm{~km}$, which might reflect the absence of shallow rupture in this area. 


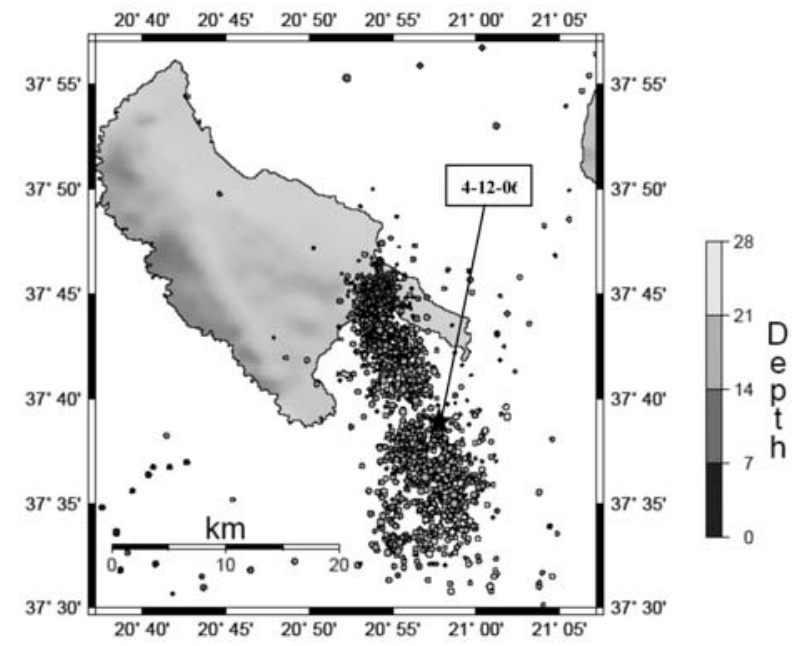

Fig. 5: Epicenter distribution map of the April 2006 seismic sequence. Approximately 1600 events are plotted with RMS $<0.1 \mathrm{sec}$, ERH $<3 \mathrm{~km}$ and $\mathrm{ERZ}<2 \mathrm{~km}$.

\section{Epicenter Distribution of April 2006 Seismic Sequence}

The intense seismic activity during April-May 2006 led the Earthquake Planning and Protection Organization (E.P.P.O.) to the installation of a temporary seismological network constituted of five digital seismographs on Zakynthos Island. The collection of seismic data for this experiment began in April 14, 2006 and lasted up to July 9, 2006. The location of all the earthquakes that were recorded during the operation of the E.P.P.O. seismological network was determined by the help of HYPO71 (Lee and Lahr, 1975) and Hypoinverse with almost similar results. On the whole, nearly 3500 hypocenters with magnitude $>1.7$ were located and 1600 of them (with RMS $<0.1 \mathrm{sec}$, ERH $<3 \mathrm{~km}$ and ERZ $<$ $2 \mathrm{~km}$ ) are presented in figure 5. Examining the epicenter distribution map, it can be observed that the seismicity is grouped in two main clusters in a general NNW-SSE direction. The first cluster is located inside the Gulf of Zakynthos Island, while the other one continues southwards. The two clusters are separated by a narrow region in which absence of the intense seismicity is observed (Chousianitis, 2009). The largest event of the sequence that was occurred on April 12 (denoted with a star in figure 5 ) and discussed earlier belongs to the southern cluster, very near to the intermediate area.

\section{Conclusions}

The most reliable source mechanisms and seismic moments of a significant number of events that occurred during the time interval from 1997 until 2009 in the broader area of Zakynthos Island are presented. Seismograms recorded by digital broadband stations at local and regional epicentral distances and at teleseismic distances between $30^{\circ}$ and $90^{\circ}$ were used. We employed two different techniques, which both allow good accuracy in the determination of the fault plane solution and ensure reliable estimation of the scalar seismic moment. For regional distances we used a moment-tensor inversion method, while for teleseismic distances we employed body-wave modeling.

The calculated focal mechanisms in the westernmost part of the studied area around Cephalonia Island clearly show dextral strike-slip motion associated with the transform zone along the Central Ionian Islands and emphasize the importance of the component of right-lateral shear within that region. This motion is consistent with tectonic studies (e.g. Underhill, 1989) GPS geodetic observations (Lagios et al., 2007; Chousianitis, 2009), and also with the focal mechanisms computed in this area (Scordilis et al., 1985; Papadimitriou P., 1988; Hatzfeld et al., 1990). Reverse faulting appears west and south of Zakynthos Island, 
along the external part of the Hellenic Arc, which is associated with crustal shortening and active subduction. Over this zone, the depths revealed by the calculated fault plane solutions varied between 10 and $40 \mathrm{~km}$. Normal faulting is observed around the Trihonis Lake, where neotectonic studies suggest N-S extension (Mercier et al., 1987). Of special interest is the area between the island of Zakynthos and the Western coast of Peloponnese where shallow and deeper events of strike-slip faulting occur.

Finally, using both methodologies we were able to study the strongest events of the seismic sequence that occurred near the southern coast of Zakynthos Island on April 2006, which is grouped in two main clusters separated by a narrow aseismic region (Chousianitis, 2009). Overall, more than 15 earthquakes of magnitude $\mathrm{M}_{\mathrm{w}}>4$ occurred for a period of two months from April until May, 2006. In all cases, the obtained focal mechanisms revealed thrust motions in a general NNW-SSE direction that may be explained by the compressive tectonics that dominate south of Zakynthos Island and can be correlated with upward motions observed for the same time period, as deduced by DGPS measurements in the southern part of the Island (Lagios et al., 2007; Chousianitis, 2009).

\section{Acknowledgments}

We would like to thank the Earthquake Planning and Protection Organization (E.P.P.O.) and especially Dr. George Papadopoulos for providing phase data from their temporary seismological network. We also thank GEOFON, MEDNET, ORFEUS and IRIS for online waveform archives. Maps and focal mechanisms have been plotted using GMT (Wessel \& Smith, 1998).

\section{References}

Agalos A., Papadimitriou P. and Makropoulos K., 2008. Rupture Histories of Strong Earthquakes. 31st General Assembly of the European Seismological Commission, held at the Creta Maris Conference Center, Hersonissos, Crete Greece, Book of Short papers, p 9-16.

Aki, K. and Richards, P.G., 2002. Quantitative Seismology. University Science Book, 2nd edition, Sausalito, California.

Anderson, H. and Jackson J., 1987. Active tectonics of the Adriatic region. Geophys. J. R. Astr. Soc., 91, 937-983.

Bouchon M., 1979. Discrete wave number representation of elastic wave fields in three-space dimensions. Journal of Geophysical Research, 84, 3609-3614.

Bouchon, M., 2003. A review of the discrete wavenumber method. Pure Appl. Geophys. 160, 445-465.

Chousianitis K., 2009. Seismic source properties and ground deformation study of the broader area of Cephalonia and Zakynthos Islands using Geophysical and Space techniques. Doctorate Thesis, Department of Geophysics-Geothermics, University of Athens, p.280 (in Greek).

Dreger, D.S. and Helmberger, D.V., 1993. Determination of source parameters at regional distances with three component sparse network data, J. Geophys. Res., 98 , 8107-8125.

Fan, G., Ni, J.F. and Wallace, T.C., 1994. Active tectonics of the Pamirs and Karakorum, J. Geophys. Res., $99,7131-7160$.

Finetti, I. and Morreli C., 1973. Geophysical Exploration of the Mediterranean Sea. Boll. Geof. Teor. ed Appl., 15, 263-341.

Fukuyama, E. and Dreger, D.S., 2000. Performance test of an automated moment tensor determination system for the future "Tokai" earthquake. Earth Planets Space, 52, 383-392.

Futterman, W.I., 1962. Dispersive body waves. Journal of Geophysical Research, 67, 5279-5291.

Hatzfeld, D., Pedotti, G., Hatzidimitrioiu, P. and Makropoulos, K., 1990. The strain pattern in the western Hellenic arc deduced from a microearthquakes survey. Geophys. J. Int. 101, 181-202. 
Herrmann, T. and Wang, G.Y., 1985. A comparison of synthetic seismograms. Bull. Seism. Soc. Am., 75, 41-56.

Ichinose, G.A., Anderson, J.G., Smith, K.D. and Zeng, Y., 2003. Source parameters of eastern California and western Nevada earthquakes from regional moment tensor inversion, Bull. Seism. Soc. Am., 93, 61-84.

Jackson, J. and McKenzie, D., 1988. The relationship between plate motions and seismic moment tensors, and the rates of active deformation in the Mediterranean and Middle East. Geophysical Journal of the Royal Astronomical Society, 93, no.1, 45-73.

Jost, M.L. and Herrmann, R., 1989. A student's guide to and review of moment tensors. Seism. Res. Lett., $60,37-57$.

Kanamori, H. and Stewart, G.S., 1976. The mechanism of the Guatemala earthquake of February 4, 1976, revealed by teleseismic surface-wave and body-wave analysis. Eos, Transactions, American Geophysical Union, 57, 950 .

Kikuchi, M. and Kanamori, H., 1991. Inversion of complex body waves; III, Bull. Seismol. Soc. Am., 81, 2335-2350.

Kikuchi, M., Kanamori, H. and Satake, K., 1993. Source complexity of the 1988 Armenian earthquake; evidence for a slow after-slip event, Journal of Geophysical Research, 98, 15,797-15,808.

Kissel, C. and Laj, C., 1988. The Tertiary geodynamical evolution of the Aegean arc: a paleomagnetic reconstruction. Tectonophysics 146, 183-201.

Lagios E., Sakkas V., Papadimitriou P., Damiata B.N., Parcharidis I., Chousianitis K. and Vassilopoulou S., 2006. Crustal deformation in the Central Ionian Islands (Greece): Results from DGPS and DInSAR analyses (1995-2006). Tectonophysics, 444, 119-145.

Le Pichon, X. and Angelier, J., 1979. The Hellenic arc and trench system: a key to the noetectonic evolution of the Eastern Mediterranean area. Tectonophysics 60, 1-42.

Makropoulos, K. and Burton, P., 1981. A catalogue of Seismicity in Greece and the Adjacent Areas. Geophys. J.R. Astr. Soc., 65, 741-762, and Microfiche GJ65/1.

Mercier, J.-L., Sorel, D. and Simeakis, K., 1987. Changes in the state of stress in the overriding plate of a subduction zone, the Aegean arc from the Pliocene to the Present, Ann. Tectonicae, 1, 20-39.

Papadimitriou, P., 1983. Etude de repliques de seismes de Corinthe (1981), Rapport de stage du DEA, IPG Paris.

Papadimitriou, P., 1988. Etude de la structure du manteau superieur de l'Europe et modelisation des ondes de volume engendrees par des seismes egeens, Doctorat de l' Universite Paris VII, Paris, France.

Papadimitriou, P., Kaviris, G. and Makropoulos, K., 2006. The Mw=6.3 2003 Lefkada earthquake (Greece) and induced stress transfer changes, Tectonophysics, 423, 7-30.

Saikia, C.K., 1994. Modified frequency-wavenumber algorithm for regional seismograms using Filon's quadrature: modelling of Lg waves in eastern North America. Geophys. J. Int., 118, 142-158.

Saikia, C.K., Woods, B.B. and Thio, H.K., 2001. Calibration of the regional crustal waveguide and the retrieval of source parameters using waveform modeling. Pure Appl. Geophys., 158, 1301-1338.

Scordilis, E.M., Karakaisis, G.F., Karacostas, B.G., Panagiotopoulos, D.G., Comninakis, P.E. and Papazachos, B.C., 1985. Evidence for transform Faulting in the Ionian Sea: The Cephalonia Island earthquake Sequence of 1983. PAGEOPH, 123, 388-397.

Thio, H.K. and Kanamori, H., 1995. Moment-tensor inversions for local earthquakes using surface waves recorded at TERRAscope, Bull. Seismol. Soc. Am., 85 , 1021-1038.

Underhill, J.R., 1989. Late Cenozoic deformation of the Hellenide foreland, western Greece. Geol. Soc. Am. Bull. 101, 613-634.

Wessel, P. and Smith, W.H.F., 1998. New improved version of the generic mapping tools released. Eos Trans. AGU 79, 579.

Zeng, Y. and Anderson, J.G., 1995. A method for direct computation of the differential seismogram with respect to the velocity change in a layered elastic solid. Bull. Seismol. Soc. Am., 85, 300-307. 